\title{
Our "Baby" on YouTube: The Gendered Life Stories of the Unborn
}

\author{
Agnès Pélage
}

ENSAE-Institut Polytechnique de Paris/PRINTEMPS (UVSQ)

\section{ABSTRACT IN ENGLISH}

This study concerns the usage of foetal ultrasounds, more specifically those produced during the $5^{\text {th }}$ month of pregnancy within the routine checks of any pregnancy in France. Interestingly, more and more parents are posting short films on YouTube of their baby-to-be using the medical images produced during such antenatal examinations. This study therefore analyses a set of 108 YouTube posts among the thousands available to understand the social implications of such posts on the unborn. Uncannily, it appears that these videos constitute not only the first pages of the biographies of a girl or a boy but also the autobiographical tales of a mother or father waiting for the birth of a daughter or son. The close reading of 31 archetypical videos reveals how those who post such videos see $5^{\text {th }}$-month ultrasound imagery as a means for them to prepare, not just for the birth of a child, but for the birth of a girl or a boy and simultaneously to prepare to become, not just parents, but the father or mother of a son or a daughter.

Keywords: life writing; YouTube; foetus; ultrasounds; embodiment; gender; parenting

\section{ABSTRACT IN FRENCH}

Cette étude porte sur les usages que font les futurs parents des échographies foetales, et plus particulièrement de celles réalisées au cours du 5ème mois dans le cadre du suivi médical de la grossesse, en France. Parmi ces usages, nous nous sommes intéressés aux vidéos que les parents confectionnent à partir de cette imagerie médicale prénatale et qu'ils postent sur YouTube. Cette étude se fonde 
sur un échantillon de 108 films disponibles sur YouTube, sur les milliers diffusés, afin de tenter de comprendre les implications sociales de telles publications. Ces vidéos constituent les premières pages de biographies d'un enfant à naître, tout comme elles livrent des éléments significatifs de récits autobiographiques de futurs parents attendant l'arrivée d'un bébé. Mais, l'analyse détaillée de 31 vidéos archétypiques montre précisément comment les échographies morphologiques du 5ème mois servent de support pour se préparer, non à la naissance d'un enfant, mais à la naissance d'une fille ou d'un garçon et ainsi de se préparer à devenir non pas des parents, mais le père ou la mère d'un fils ou d'une fille. Cet article propose une contribution à la réflexion sur les mécanismes de construction précoce du genre, avant même la naissance.

Motsclés: récit de vie, YouTube, fotus, échographie, corporéité, genre, parentalité

How does a life story become gendered? How far can we go back in a life story to grasp the mechanisms of gender building? In an attempt to answer these questions, this article explores the role of medical imagery in the very early social construction of gender, in France. More precisely, it focuses on the images produced by the ultrasound examination of the foetus performed during the $5^{\text {th }}$ month of pregnancy. In France, such morphological examinations take place between the $20^{\text {th }}$ and $24^{\text {th }}$ week of gestation and are part of the standard medical protocol for the monitoring of any pregnancy. It is also during this standard pregnancy examination that-according to the French national Elfe ${ }^{1}$ survey-nine parents out of ten ask to know the sex of the foetus.

During the 1980s, medical practitioners drew attention to the ethical issues brought about by new advances in foetal imagery and surgery, capable of transforming the foetus into a patient (Fletcher, 1981). The social impact of this novel technology was explored by Rosalind PollockPetchesky (1987) who saw the dissemination of the new medical imagery as a strategic tool in the social building of the foetus as 'a person'. In 1991, Haraway and then Duden (1993) exposed how this new focus on the foetus also impacted the mother. In 1997, Mitchell and Georges, and then Casper (1998), exposed how medical imagery and more especially 4D ultrasound technology (Roberts 2012) has today empowered the foetus and subsequently disempowered the mother. Indeed, the whole field of obstetrics has been redefined by a new, 'foetocentric' trend which has made ultrasound examinations an instrument of 'prenatal diagnosis' and 'foetal surveillance' (Leaver 2017) and removed the obstetrician from his/her primary role as the physician of the mother to that of the physician of the foetus.

What is more, today, the images produced during antenatal examinations are now being published on social media, leading to what Janelle 
S. Taylor (2008) calls the 'public' foetus and to what Deborah Lupton (2013b) sees as the elevation of the foetus to a fetishized icon.

Examining how the morphological ultrasounds produced by medical practitioners are used by parents to generate narratives and analysing how they constitute not only the first pages of the biographies of a girl or a boy but also the autobiographical tales of a mother or father waiting for the birth of a daughter or son is the object of this article.

\section{Methodology}

In order to conveniently study this dual process of gendered biographical and autobiographical production by YouTube users, an Internet search was initiated using the YouTube search engine. On 30 th April 2017, the YouTube search engine counted roughly 103,000 videos associated with the terms "foetal ultrasound" dating back to the very first posts in 2007. When limited to videos in French using the French search words 'échographie foetale', this number was conveniently reduced to $\mathbf{5 , 9 0 3}$. By then refining the terms of the search to 'échographie morphologique', which is the more specific name of the standard $5^{\text {th }}$-month pregnancy examination, this brought down the number yet further to $\mathbf{1 , 6 4 0}$. By adding the term '3D' to 'échographie morphologique', the YouTube search engine reduced the number of hits to $\mathbf{1 , 1 9 0}$. The three-dimensional (3D) ultrasound technique is now the most commonly used form of ultrasound imaging of the foetus. Such 3D imagery allows better contrasts between organs and tissues by reading two-dimensional (2D) images in different planes of space. Four-dimensional (4D) images allow the acquisition of real-time motion (moving 3D images). By searching for 3D antenatal ultrasonography, all of these technologies are represented. Indeed, for over a decade, 'most ultrasound equipment manufacturers have incorporated 3D/4D technology into their scanning systems, and 3D/4D is used worldwide today' (Merz and Abramowicz 2012, 336).

A second level of selection involved painstakingly eliminating, one by one, from these 1,190 videos, any advertisements by doctors or clinicians, tutorials explaining ultrasound examination procedures, professional development sessions for medical students or health professionals or school videos, conventions of professional associations, medical television programs and E-zines, foetal imagery which did not concern the monitoring of a $5^{\text {th }}$-month pregnancy, veterinarian foetal imagery and videos by 'prolife' associations. Basically, only the videos posted by parents or family members and actually referring to the sex of the foetus, either in the title of the video or in the comments of parents or Internet users who accompany it, or in the video itself were kept. For example, the 3D foetal ultrasound videos selected indicated a first name or the sex by using terms such as 'girl', 'it's a boy', 'our little guy', 'my princess', 'John 
Jr.', etc. All vlogs were also dismissed and so too were any duplicate hits. This brought the number of videos under study to 108 short films.

In order to arrive at a corpus of reasonable size for the purposes of this article, $\mathbf{3 1}$ archetypical videos were finally chosen. These are practical tokens of the basic narrative variations found among the previously selected videos. This selection was achieved by grouping the 108 posts according to the number of characters involved and the complexity of their narratives. Indeed, some posts rely nearly exclusively on ultrasound imagery and therefore focus nearly exclusively on the foetus, while others add further layers of signification and characters, thus complicating the raw medical imagery. For example, visual and audio elements (through camcorder shots taken during the ultrasound examination, running oral or written commentaries by the parents of the scans shown, the recorded presence of other members of the family during the antenatal examination, and added soundtrack or non-medical imagery) are a more sophisticated usage of the initial medical imagery. ${ }^{2}$

The final 31 documents last between 26 seconds and 9 minutes 15 seconds and are numbered from 1 to 31 . This numbering guarantees the anonymity of the posters and the people involved. Using the same keywords as those selected for this research will retrieve the very same posts, or other variations, and will therefore be of a very similar nature to those of the corpus analysed here. Finally, because the videos were not posted knowing such a study would be undertaken, the names, places or any indication likely to formally identify the protagonists were modified so as to hide the identity of all concerned.

The present study therefore does not allow the formal identification of any of the social characteristics of the YouTube posters nor does it allow inscribing the posts in any social context other than that of a social practice that is now widespread: the sharing of the parental experience of a pregnancy on YouTube.

\section{DETERMINING THE SEX: FROM A FOETUS ... TO A BABY GIRL OR BABY BOY}

In order to generate a narrative of a baby-to-be, YouTube posters bring their spectators to re-live the important stages in the ultrasound examination experience they underwent at the moment of the $5^{\text {th }}$ month morphological examination. During this standard examination, the pregnant woman is laid down and an ultrasound scanner (a transducer) is placed against her belly. Manipulating the transducer is the sonographer (a doctor or midwife), seated in front of a screen showing alternating 2D, 3D and/or 4D imagery of a foetus. The videos resulting from this 
examination-and that are studied here-are post-produced thanks to sounds and images recorded by a third person (who is often clearly the father) or through the compilation of excerpts provided by the sonographer and handed over at the end of the examination. In some cases, the children of the couple and/or the grandparents-to-be may also be present. The narratives thus generated, more or less explicitly reveal the stages of the construction of the corporeality of the foetus, expose the feelings of empathy of those present towards this baby-to-be and narrate how the sex of the foetus was determined.

\section{Telling the Stages of the Construction of a Corporeality}

A first, explicit dimension in the narratives studied concerns how those posting the videos acceded to the corporeality of the foetus. Maternal anatomy being an obstacle in the visualization of the unborn, the sonographer's first job is, it appears, to visually separate the foetus from the body of the mother. For this, the sonographer may point out what is the belly of the mother, the uterus, the placenta, the amniotic fluid, the umbilical cord and the foetus proper. Another solution, as it appears in the videos posted, is purely and simply to expunge the umbilical cord or any other element present on the screen that is not the foetus. Video 31 illustrates this separation when the sonographer explains how to interpret what is on the screen by saying: 'The baby's head is up here...for the moment. Bottom down here. The placenta here: it's the grey cushion we can see situated in front, at the level of your belly. Everything black is liquid. What is very white are the bones we can see.'

Once the attention of the parent is properly focused on the foetus, the body of the baby-to-be is then revealed. In Video 11, this is shown to be a difficult and progressive task:

Sonographer: The fingers. The little feet, here. There, a hand. Here now, a foot, there.

Father: Ah ha!

Sonographer: A part of the face. The two eyes and the mouth. Its little hands.

Mother laughs.

Sonographer: The heart. The two hands. The heart. You can see it from here.

Mother: Oh yes!

Sonographer: The heart.

Mother: Wow!

Sonographer: The bladder, the whole belly, its ribs. The legs stretched out here. 
Further anatomical landmarks and structures such as the head and the spine can be examined and even measured. These also include internal organs such as the foetus' stomach, kidneys, ribs and brain. Facial features, hands, feet, fingers and toes and genitalia are also usually pointed out when they appear on the screen. The imagery concerning one organ, carrying apparently more importance than the others, is the foetus' heart. Indeed, the heartbeat is always monitored during the examination and the sound of the foetus' beating heart is nearly always posted. In Video 5, for example, there is no sound track accompanying the sonographic imagery at all, except the rapid swoosh swoosh of a heartbeat. In Video 13, the sonographer is shown not only recording the sound of the beating heart but colour images, taken from the ultrasound imagery, show how the foetus' blood is flowing through the four cavities.

It is therefore now a 'baby patient', designated semantically as such, that is being examined by a practitioner and no longer the mother carrying a foetus. The mother's body becomes marginalized as the focus of attention centres on the foetus, its morphobiology and its movements. Depending on the position of the baby-to-be, however, only partial and blurred views can usually be seen: a hand, the profile, a leg and foot, a beating heart, etc. It is the sum of these anatomical parts that build up the image of a whole. Of course, building an organic body from a series of unfamiliar views is only possible thanks to the sonographer who comments, decodes, translates and gives meaning to the blurry and moving images. Video 7, for example, begins with a close up of a monitor screen on which appears a white foetal form within a dark womb. In the course of the exchanges between the doctor and the parents the spectator learns that the shape represented on the screen measures $5 \mathrm{~cm}$. At this point the doctor says: 'Look. We can see the baby clearly. It's moving well.' It is thus, to a large extent, the sonographer who contributes actively to the writing of the first paragraphs of the life story that the parents want to tell. It is the sonographer who, as gatekeeper, designates what should be looked at and what can be seen. In Video 20, for example, the father clearly struggles to identify the different parts of the foetal anatomy and to see the foetus as a whole. The sonographer therefore feels that he must go over the entire process of identification once more with the parents, in order to be properly understood:

Father:

Is that the head?

Sonographer: No, that there is the belly, with the heart.

Father: Ah! That's the belly...

Sonographer: I'll start again from scratch then. 
Because seeing is not necessarily understanding, the YouTube posters, by posting their own hesitations and the unveiling of the body of the foetus as a whole, aim to help the viewers of their posts not to make the same mistakes as themselves, and to clearly understand their interpretation of what the sonographer is pointing out: a fully-fledged baby.

The role of certain parts of the body in the process of corporealization and individuation of the foetus has been largely researched. In an often referenced study on pregnancy loss, for example, the anthropologist Linda Layne (2000) explores how images of hands and feet, of fingers and opposable thumbs, are extrapolated by mourning mothers as exterior signs of how their 'would-have-been babies' were, for them at least, 'real babies'. In her pioneering research focusing on 2D antenatal sonography in the late 1990s, Lisa Mitchell also considers the mechanisms of human recognition: 'the beating heart signals viability and draws on the popular idea of the heart as the source of life, vitality, and whatever it is that animates people' $(2001,126)$. What remains, however, is how this recycling by parents of ultrasound images-and the running commentaries of the sonographers generating them-manages to plant the seeds of a very precocious biography.

\section{Narrating the Birth of Empathy}

Simultaneous to the process of corporealization of the foetus, YouTube posters also offer viewers the chance to re-live what they experienced emotionally during the ultrasound examination, by having viewers go through the same processes of empathy they went through.

One of the steps towards empathy is to show how what has been identified as a living organism is not just present, but is active and spirited. In the videos, the foetuses are shown to have minds of their own: motives are forwarded to explain their in utero activity. It is 'pulling its tongue' (Video 22), it is 'a baby swimmer' 'doing gymnastics' (Video 7), it is thought to be seen 'scratching its nose' (Video 16). In Video 24, the doctor first says 'He is hiding' and later, as the foetus moves its legs, he adds: 'He's a little athlete'. The foetus is even sometimes said to be 'grasping its foot', 'putting its hand in front of its face' or 'running away' (Video 30).

When the foetus is not moving at all, it is said to be 'resting' or 'sleeping' or, as in Video 30: 'He seems to be calming down now'. This individuation of the foetus is further heightened by the insertion of terms of endearment throughout the scientific examination, as in this example from Video 15: 
Sonographer: Here we are. A nice little profile. Here, with the little hand in front.

Mother: $\quad$ The hand is in front.

Father: Is that the hand? Father laughs.

Sonographer: And the small tip of the nose, the small mouth, the chin that's protruding well. We can even see it gulp a bit. That's a really nice little profile there.

The repetition of the subjective term 'nice' by the sonographer is an encouragement for the parents to identify with the foetus and to see it as a 'nice', 'little' human being and even to interact with it. Accordingly, in Video 17, the father asks if the foetus can hear their conversation and this is confirmed by the sonographer. The foetus is then described as 'happily smiling.'

Thus, in order to write the very first pages of the biography of the unborn, the future parents explain how they were 'shown' and how they were brought to 'see' the first images of the baby-to-be and how they were trained to build a series of initial emotional 'bonds'. In fact, the impact of antenatal ultrasonography on the mother-foetus relation has been seen as having a positive (Black 1992, Di Pietro 2010), indifferent (Metz and Abramowicz 2012) or even negative impact (Gregg 1995). Moreover, bonding to a foetus that can be seen only through ultrasound images signifies bonding to a hybrid figure that is, in fact, half-organic half-technological: it is a 'technofoetus' (Casper 1998, Palmer 2008). Through the lens of technology the foetus becomes a storyboarded 'baby-to-be', ascribed intentions and feelings and even assigned a personality. Through what Robert (2012) names 'collaborative coding', parents construct a network of meanings-sometimes medical, sometimes emotional, and sometimes cultural-to transform ultrasound images of a foetus into the story of a baby.

Hence, the YouTube posts under analysis do not reduce the sonographer's work to a purely technical procedure. On the contrary, the sonographer's work contributes to the fabrication of a bond, which the posters, in turn, seek to generate with the spectators of their posts. In fact, it appears that the edifice of the biographical narratives initiated by parents in their YouTube posts involve the appropriation of sonograms and sonographic examinations perceived as an objective vision of the foetus but actually the product of a collective coding of foetal imagery that now organizes a further semantic shift from 'a' baby to 'my' baby. At this point, the morphological examination of the $5^{\text {th }}$ month becomes a turning point in the transition towards parenthood, especially for fathers (Sandelowski 1994). As a window into the interior of the woman's body, sonographic images 
provide 'visual knowledge' and a 'means of knowing the baby' which do not depend on the 'embodied knowledge of the woman' (Draper 2002, 780-781). For many, it constitutes a rite of passage towards parenthood.

\section{Narrating the Determination of the Sex of the Foetus}

A last dimension in this process of embodiment and empathy, as it is ostentatiously displayed in the YouTube posts under study, is the importance given to determining the sex of the foetus. Those posting the films explain how they clearly want to have the sex of the foetus formally identified, are even impatient to know the sex of the baby-to-be, and are openly disappointed if this information cannot be provided. Indeed, in the choice of the sequences they have posted, Youtubers bring their audiences to re-live their desire to have this key information unveiled. For example, after having been shown all the healthy vital organs and having seen the outline of the foetus' profile, the poster of Video 27 tells of the father's desire to know the sex of the foetus by recording his words during the ultrasound examination.

Father: And besides that, could we see its sex?

Sonographer: We will try to see if...

Father laughs nervously.

Sonographer: Has it already been identified?

Father: No. No. They didn't see it. We have never looked.

In many similar cases, parents tell of their impatience to have the sex of the foetus unveiled. In Video 17, for example, the mother emphatically says: 'Yes, I MUST know.' But to return to Video 27, when the sonographer does not manage to get a clear image of the sex of the foetus, the mother accepts having her belly ploughed by the sonographer during the examination in order to obtain the information eagerly awaited: 'I'm not pushing you around too much there, am I? I'm not hurting you too much?'

If the sonographer is finally unable to identify the sex of the foetus with certainty, parents openly show their disappointment or regret. 'Oh... What a pity...' says, for example, the father in Video 7. Thus, the spectator seems to be invited to understand that as long as the sex of the foetus remains a mystery, proper personification, identification and recognition as a member of the family is difficult. This is clearly the case during one ultrasound scan which ultimately does not reveal the sex of the foetus and which leaves the child present (in Video 7) as still seeing the foetus as a 'baby clown' or 'baby fish', 'inside, stuck inside'. 
Lisa Mitchell adds that in her study too some women, when they were told the sex of the foetus, suddenly 'felt different' or 'closer to the baby' (Mitchell 2001, 154) and were able to identify better with the baby-to-be: 'When it's not sexed, it's just an extension of me' (Mitchell 2001, 159). It therefore appears that letting the whole world see the sex of the foetus is not the same as only posting images of the hands, legs or even a pretty profile. This is because revealing the sex is the ideal moment to shift from a medical narrative to a truly cultural life story. It is the occasion for a semantic shift from the sexual distinction of 'male' or 'female' to the gendered categories of 'girl' or 'boy' through medical authentication (Larkin 2006).

Therefore, seeing the visual artefact on the screen and hearing the discourse of the sonographer is not enough. What really counts is to know the sex of the foetus, as it is this crucial information that enables the parents to see the baby-to-be as 'their' baby. When the sex is clinically established, the story of the foetus can truly become a life story or, more precisely, a gendered biography.

\section{A GENDERED BIOGRAPHY OF AN UNBORN CHILD}

The second part of this study is an attempt to unravel how the posters of the YouTube videos construct gendered narratives around the babies-to-be, by mobilizing particular sequences of images and sounds produced by the morphological examination. Indeed, whether the film of the examination is posted in part, in full, or as a montage, YouTube posters stage a life story that has nothing to do with any medical reality but is loaded with cultural connotations weighing on the baby-to-be. When it comes to telling - somewhat paradoxically - the story of the foetal life of the unborn, four archetypical narrative constructions are identifiable.

\section{A Narrative, Without Commentary, Built on a Close-up on the Sex of the Foetus}

This first narrative construction, of which there are many thousands on YouTube, has only one main character and can be considered as the simplest type of narrative plot of all.

Typically, these posts are limited to a close-up on the genital bud of the foetus. Video 1, for instance, offers nothing more during the whole 26 seconds of the post. It is as if, everything is being said through a short sequence of 4D imagery that the YouTube posters carefully selected for their intended audience. It is as if, the individual story of this foetus begins with this male genital bud, which becomes the very condition for 
the development of any future narrative. Besides a partial and, as usual, imperfect view of the rest of the body of the foetus and perhaps a musical soundtrack or the recording of a beating heart, nothing accompanies this first category of narrative. Any reading therefore tells more about the viewer's representations than about those having posted the document. In fact, this video mobilizes, above all, the spectator's imagination and the stereotypes of gender that structure his or her imagination. The narrative offered, though apparently simple and closed, is therefore paradoxically extremely open to interpretation.

\section{A Narrative Organized Around the Medical Procedure Used for Determining the Sex of the Foetus}

The second type of archetypical plot structure blends segments of ultrasound imagery (as those existing in the first category) to the written or oral discourse of a sonographer. That is to say that the images and the sounds produced by the ultrasound device are accompanied by the sonographer's comments, recorded in context. By adding this further dimension to the narrative, the sonographer now appears as another main character in the story told. In this second type of narrative, the sonographer's gestures, words or text-typed-onto-the-ultrasound-imagery narrate the sex of the foetus. In Video 26, for example, in order to confirm the sex very clearly for the parents, the sonographer points with her finger at the sex of the foetus, draws the contour of the external genitals (labia) and then types, in capital letters, the word "GIRL".

It is now not just blurry sonographic images that structure the life story, it is the medical discourse that has allowed, and even justified, the gendered narrative. Moreover, it is interesting to note that it is generally the sonographer, who is the first to consider the foetus as a person and to operate a semantic shift of the category of sex into a gender type. To take just one example from Video 10, but there are many more within and beyond the corpus studied, when announcing the sex of the foetus, the sonographer says: "You can start thinking about a boy's name if you haven't thought of one already."

\section{A Narrative Built on Reactions to the Announcement of the Foetus' Sex}

In the third archetypical narrative construction, the imagery of the ultrasound examination and the discourse of the sonographer are also used. It, however, adds to these two dimensions by highlighting the visible and/ or audible presence of the parents and sometimes other family members. 
In this example from Video 14, the grandmother is present and her comments are clearly part of the film:

Sonographer: Then, let's have a look at the sex.

Mother: Ah!

Sonographer: There you are.

Close-up on genital bud.

Mother: A little boy!

Sonographer: Yep!

Mother: Yipee!

Father laughs.

Sonographer: Here, you have one leg, and there, you have the other. And there the willy.

The cursor circles the genital bud.

Grandmother: Oh dear! Because the grandmother has come to see him, he thinks: I have to show it off to her.

General laughs

Mother: Now, it's clear!

Grandmother: Oh yes it is!

In this excerpt, the grandmother's comments do not just acknowledge a sex or place the foetus into a sex category. What they do is to produce gender through the activation of a gender stereotype: that boys like to show off their manhood. Incorporating into the filmed narratives the additional character of the grandmother thickens the plot in which the gender of the unborn is co-built. This third type of narrative again shows how gender is shaped by a raft of social interactions predating the moment of birth.

\section{A Narration Around the Affirmation of Gender}

All the films posted have been edited in some way. The fourth and last narrative construction, however, is based on the very potentialities of this editing process. In these videos, the ultrasound imagery or the sequences recorded during the morphological examination are only partial elements of the narrative as a whole. An elaborate parental work of montage adds a whole new dimension to the story told. For example, written text or a musical soundtrack is added by parents to the raw ultrasound images. The aesthetic choices made are often stereotypical, such as the adding of flowery motifs for girls or the obvious presence of the colour blue for boys. These associate the tale of the foetus to a gendered universe that is being constructed around its ultrasound imagery. Video 18 is an example 
of such a montage. In this video, the captions 'Your feet', 'Your little fingers', 'Your bottom', etc. have been added to framed shots of ultrasound imagery and to shots recorded by a third party during the examination of the mother. More especially, the words ' $100 \%$ girl' have been added just after the screen shot of the foetus' labia. The choice of the musical soundtrack too reinforces the gendered message by referring to a father's love for his daughter. Finally, the pink colour scheme of the post makes this video the clear announcement of what is presented as a 'girl' foetus using medical imagery as indisputable proof of what, in fact, has been painstakingly construed with the help of reproduced social connotations.

Through the four narrative usages of ultrasound imagery presented, what the YouTube posters are trying to do becomes obvious: by recycling the medical data allocating the foetus a sex category and subsequently performing gender, they are announcing the social birth of their future gendered child before its actual delivery. This is explicitly the case in the final sequence of Video 22 where the name, size and weight of a foetus are announced in exactly the same way as on traditional birth announcement cards... only several months too early.

Gemma measures about $25 \mathrm{~cm}$ and weighs approximately $550 \mathrm{~g}$.

She is as fit as a fiddle!

See you soon!

By adding their own gender representations to images of a sexed foetus, YouTube posters are therefore anticipating the gender socialization of their future child. As a consequence, it can be said that gender-specific characteristics are not just built up over a life time: they are imposed upon the foetus even before it is born. Yet this founding moment in the now clearly gendered biography of the foetus is also a key moment in the parental autobiography. This is the dimension explored in the next part of this paper as it analyses how the fabricated foetal biographies are simultaneously inserted within broader gendered parental autobiographies, and more broadly still, into gendered family histories.

\section{A GENDERED PARENTAL AUTOBIOGRAPHY}

Making the foetus visible in this way does not so much make the mother invisible (Pechevsky 1987, 277; Rothman 1986, 113) or reduce them to simple incubators (Williams 2005). As Lesley Larkin has written, pregnant women 'become visible as properly gendered mothers of properly gendered children' (2006, 273) and 'authentic mothers "prepared" for 
the gendered identities of their unborn' (2006, 282). Beyond simply initiating the biography of an unborn child, the videos analyzed also show the autobiographical tales of parents revealing a change in their social status: as a couple, they present themselves as parents-to-be; as parents, they show themselves as adapting to the idea of becoming the parents of an extra child and; as a family, they present themselves as a growing unit. Therefore, what now requires examination is how these gendered foetal biographies are inscribed within parental autobiographies and whether, in the parental autobiographies thus generated, further gender stereotypes come to weigh on the unborn. Indeed, in all the posts, the upcoming parents all tell (again, more or less explicitly) of how they must adjust to the sex revealed and prepare for the arrival of the baby-to-be.

\section{A Parental Adjustment to Gender}

In the autobiographical content of the posts under study, many parents happily accept the doctor's results. This is made clear, for example, through the recognition, in the ultrasound imagery, of characteristic family traits: same big feet as the father, same features as an older sibling. In Video 17, for instance, the foetus is said to have the same small head as his elder brother. In Video 19, where the narrative has the foetus itself telling its own story, the poster has written under the sonographic images of its profile and legs, 'I have the same profile as my dad' and 'long legs like Mom'. In Video 9, the mother laughingly adds that the foetus has inherited its father's big feet. Uncannily, this last remark, about the resemblance to the father, only comes once the sex is identified and after a series of more neutral descriptions was forwarded by the sonographer concerning 'small hands', 'small fingers', 'small arms' and 'small feet'. Once announced, however, the sonographer and all involved adjust their discourse-now gendered-to the sex revealed.

In other posts, on the other hand, the future parents openly show or suggest that it took them time to get used to the sex of the foetus. It appears that many had to acclimatize themselves to the sonographer's verdict, as this was contrary to their hopes, expectations or intuition. For example, in Video 13, though the mother understands the sonographer's hints and is happy, the father, who is apparently hoping for a son, struggles to accept the clues given by the sonographer:

Sonographer: So, do you want to know what it is? Do you have a preference?

Mother: I'd say a girl.

Sonographer: You want a girl. And your boyfriend, what does he want? Father: A boy. 
Sonographer:

Mother:

Mother laughs.

Sonographer:

Father:

Mother laughs nervously.

Father:

The sonographer confirms: It is a little girl.

In Video 26, in a very casually and neutral tone, the sonographer says to the mother, father and child present:

Sonographer:

Mother:

Sonographer:

Mother:

Sonographer:

Father:

Sonographer:

Mother:
There is a father who won't be happy. And there's a mother who will be pleased.

It's a girl!

I'll let you think about it. I'll let you guess what it is.

A boy.

It's a girl... that...

She laughs nervously.

It appears to be a girl.

Ah you saw again that it was a girl?

You don't really think it can grow one just like that...

No. No. It's him. He's the one who is still hoping...

Yes well. But no. I don't think so.

... Silence

When it's a girl, there's...

No. No. He can't get to grips with the idea

The sonographer clears his throat and looks for a clear image of the foetus' genitalia. He points his finger to the screen and traces the contours of the labia.

Sonographer:

We'll write it in capital letters then, because...

He types the words GIRL in capital letters over the sonographic images. The mother and the doctor laugh. The sonographer then carries on his examination with no further comment from the father.

Sonographer:

Right then. The foot.

Child speaking to his/her father: You're out of luck.

Gendering the foetus therefore appears to be a way for the parents to process their own lives, to prepare themselves for a future that they are happy to embrace or not. In parallel, it is a means for parents to prepare a place for the yet unborn among siblings.

The presence of children during the examination and the posting of their reactions also appear to be a means of recounting how, during the parental journey, it was necessary to take into account big brothers or 
sisters, to help them make room for the future newcomer. 'He won't eat you,' says the mother in Video 7 to her worried child. In Video 17 too, the mother says to her child: 'We'll see if it's a little brother or a little sister', and the father says to his son: 'Did you see, he's smiling at us'. It therefore appears that the enthusiastic narratives or the narratives of adjustment reveal just how important it is for families to be able to assign the foetus a gender as this enables them to see themselves as parents. To envision themselves thus, it appears that they have to be able to see themselves as the mother or father, of either a son or a daughter. For siblings too, only the arrival of a brother or a sister seems to make sense in their minds. Ultimately, therefore, what the YouTube posts reveal is that the gendering of the foetus is considered crucial for the unfolding of the foetus' future story and that of the family as a whole.

\section{Preparing Gender while Preparing for the Gender}

Another element of the parental narratives revealed is that parents appear to find it important that the baby-to-be conform to their gender expectations. First names, for example, are one way of preparing all concerned to a future gendered existence. As Linda Layne has written: 'Many elements once associated with social birth, including naming and/or nicknaming, are now sometimes initiated during the very early stages of a pregnancy' $(2006,47)$. This phenomena she adds is 'often accelerated once the sex of the foetus is known'. As Barnes' study on pregnant women confirms: 'None of the women formally named their unborn baby when they were unsure of its sex; even though it would be possible to do so simply by choosing a gender neutral name' $(2015,197)$.

Giving a name to the foetus is therefore a means for parents to better prepare for the birth of their child, as this, more often than not, crystallizes gender. In the YouTube videos under study here it is either in the titles or within the videos themselves that the name of the future baby is publicly revealed, perhaps for the very first time. None of the names announced are gender neutral. In that way, the parents clearly put forward the coincidence between gender (a girl's name or a boy's name) and the sex attributed to the foetus by the doctor. In France, this is in no way extraordinary. In French, gender-neutral names are very rare and only concern a very small percentage of the population, as Coulmont (2011, 66) has pointed out. Finally, it must be reminded that French law links physical appearance to the gender announced on the birth certificate. Thus, to take just one example, those who wish to be identified as belonging to another gender to that originally declared can only do so if their body bears the tangible signs of a transition, following a sex change operation for example (Coulmont 2016, 78). 
Another well-known means of preparing for birth in a gender-specific way can be seen in how parents prepare the foetus' future room or its future clothes. In Video 17, the parents ask to know the sex of the foetus and warn the sonographer that the sex must be revealed because they will be going to IKEA after the consultation and need to know whether they should be preparing for a girl or a boy. In a similar fashion, in Video 27, the sonographer asks if the parents have a preference. The father replies that they do not, but they would like to know: 'in order to buy things, clothes, etc.'

Such remarks are today very common and go to show just how much medical imagery (Taylor 2000) or keepsake ultrasounds (Kroløkke 2011, Roberts 2012) have contributed, over the last thirty years, to make the period of pregnancy an opportunity for consumption in the name of the foetus and of the foetus per se. They also confirm preparedness before birth is a 'gendered affair' in more ways than one, even in families that Bourdieu (1980) categorizes as the cultivated middle class who wish to distance themselves from gender stereotypes, as described in recent French research (Samuel et al. 2014, Rollet and Pélage 2014, Pélage et al. 2016). Mobilization during the preparatory stages is organized in a gender-specific way for the parents, and depending on the gender category assigned to the baby-to-be. This is partly the result of the baby industry which organizes a gendered child care market, and gender specific clothes and toys for babies. But the researchers also trace how the everyday practices of the two parents also contribute to prepare the normative educative framework in which the baby is later inserted. The beginnings of gender socialization are especially visible in the way the clothes and the space reserved for the baby-to-be are prepared. This is particularly the case for a second child, where couples not so much adapt the decoration of the bedroom space if the sex of the second child is different to that of the first, than organize a completely separate, even if small or later space (Rollet and Pélage 2014). Moreover, for these same mothers, for it is largely they who take on the job, 'the aim is to [...] prepare the babywear giving feminine or masculine appearance' (Pélage et al. 2016, 33). The clothes belonging to a big brother or sister, which could potentially be handed down, are selected more drastically when the baby-to-be is of a different sex, along classic rules of 'gendering': color codes, accessories, shapes. Finally, 'the eliminated clothes are more frequent when it comes to masculinizing a set of girl's clothes: pink items or anything bearing the color pink is systematically eliminated' (Pélage et al. 2016, 33). These, however, can be worn under other clothes, but only within the strictly private circle of the nuclear family.

Last but not least, the videos show how parents already address the foetus in a gender specific way. Video 25, for example, announces not just 
a boy but a son, through a montage incorporating foetal imagery, music, a voice over and captions. The foetus is addressed as 'Lucas Jr.', a heroic non-diegetic soundtrack accompanies the edited imagery and captions have been inserted:

Caption: The day has come for us to see you again.

Images of profile and then cranium from above, backbone and beating heart. Music becomes louder.

Clear profile shot of foetus.

\section{Caption:}

Here is your handsome little profile.

Heart beat is heard:

Caption: $\quad$ Your little sportsman's heart.

Bladder is scanned.

$\begin{array}{ll}\text { Caption: } & \text { Your little bladder, with colors. } \\ \text { Caption: } & \text { And at last the moment of revelation... }\end{array}$

The voices of the parents discussing are heard as unclear sonographic images appear on the screen.

Sonographer:

Mother:

Father:

Mother enthusiastically: A boy? It's a boy!

Sonographer:

Mother:

She laughs happily

Caption:

Music becomes louder as an image of a reclining foetus appears.

Caption:

And you already know the position required for a nap...

The credits of the film then unroll with the name Lucas W. as "Main Actor".

In order to be fully prepared for the birth of the unborn Lucas, it appears that the parents are already addressing the foetus according to who they expect 'he' will be: 'he' will be handsome, like sports and siestas and become a main actor in society. Such shifts in vocabulary and perceptible changes in behaviour are part of a phenomenon already noted by Medora Barnes (2015) in her sociological study on how mothers, after learning the foetal sex during pregnancy, 'projected gender onto the foetus and then began interacting with it in [...] strongly gendered ways' $(2015,200)$. Barnes considers these practices as a form of anticipatory socialization which not only concerns their new role as 'mother' but also the more specific gendered role of 'mother-of-a-son' or 'mother-of-a-daughter' (2015, 188). French sociologists Pélage et al. (2016, 44-45) have also noted in 
their qualitative study concerning the representations of parents from culturally-privileged social categories that: 'knowing the foetal sex fires off in parents a propensity to anticipate, as soon as possible, the future relationship they will have with their child by inscribing this within a gendered bond, be it in matters of education-namely in the very gendered games they plan on giving their child-or in matters of their anticipated affective relations'. Though engaging in reflexive thinking on gender, couples from the more culturally-privileged social categories also see their future selves in accordance to those qualities they see as more particularly masculine or feminine. They call upon very traditional gendered dispositions in matters of attitudes, personality, tastes (calm versus agitated, shopping with the mother versus gardening with the father, dolls versus other toys, etc.) which lead parents to consider that having a son or a daughter, for a mother or a father, is not precisely the same thing. Moreover, not knowing the gender does not mean that gender is not at the heart of the prenatal preparation.

\section{CONCLUSION}

In all the videos studied, the biographies of the foetuses and the autobiographic narratives of the expectant parents are thus inevitably gendered. The tale of the foetus becomes that of a son or a daughter told by parents transformed into fathers and mothers. This reveals how ultrasound images, edited by parents and posted on YouTube, are the fruit of a series of specific birth preparation modelling, precociously formatting, perhaps even grooming the foetus to grow into parental representations of what is a boy or a girl, a son or a daughter and to comply to deepening gender divides. It appears that for the parents having posted such videos, gender is purely and simply the foundation stone of any life story. Clearly attributing a gender to the foetus is, for them, the only way to prepare themselves as parents and to be materially prepared to welcome the baby-to-be.

As for YouTube, it is the mouthpiece that not only broadcasts these precociously anticipated gender identities as far and wide as possible, but it is also a means of recording the early traces of gender, of testifying and even of proving -through what has been staged as a clinically validated procedure- the foetus' future gender identity.

Studying such public usages of ultrasound imagery reminds that gender is a fundamental dimension of social organization and that the body, in its materiality, plays a key role. This analysis shows just how deeply anchored the roots of gender truly are: far from simply recording 
morphological foetal differences, the videos offer gendered life stories which will, throughout their later lives as babies, children, youths and adults, nurture the deep inequalities between the sexes. They are videos of gender in gestation.

\section{WORKS CITED}

Back, Les, and Nirmal Puwar. "A Manifesto for Live Methods: Provocations and Capacities." The Sociological Review 60 (2012): 6-17.

Barnes, Medora W. "Anticipatory Socialization of Pregnant Women: Learning Fetal Sex and Gendered Interactions." Sociological Perspectives 58.2 (2015): 187-203.

Barthes, Roland. "Le message photographique." Communications 1 (1961): 127-138.

Black, Rita B. "Seeing the Baby: The Impact of Ultrasound Technology." Journal of Genetic Counseling 1 (1992): 45-54.

Bourdieu, Pierre. Le sens pratique. Paris: Editions de Minuit, 1980.

Boyd, Danah, and Kate Crawford. "Critical Questions for Big Data: Provocations for a Cultural, Technological and Scholarly Phenomenon." Information, Communication E Society 15.5 (2012): 662-679.

Burgess, Jean and Joshua Green. YouTube: Online Video and Participatory Culture. Oxford: Wiley, 2009.

Butler, Judith. Undoing Gender. New York and London: Routledge, 2004.

Casper, Monica. The Making of the Unborn Patient: A Social Anatomy of Foetal Surgery. New Jersey: Routledge University Press, 1998.

Chateauraynaud, Francis. "Trajectoires argumentatives et constellations discursives. Exploration socio-informatique des futurs vus depuis le nanomonde." Réseaux 6.188 (2014): $121-158$.

Coulmont, Baptiste. Sociologie des prénoms. Paris: La Découverte, 'Repères', 2011.

Coulmont, Baptiste. Changer de prénom. De l'identité à l'authenticité. Presses Universitaires de Lyon, 2016.

DiPietro, Janet A. "Psychological and Psychophysiological Considerations Regarding the Maternal-Foetal Relationship." Infant and Child Development 19 (2010): 27-38.

Draper, Jan. "It was a Real Good Show': The Ultrasound Scan, Fathers and the Power of Visual Knowledge." Sociology of Health and Illness 24.6 (2002): 771-795.

Dubow, Sara. Ourselves Unborn: A History of the Foetus in Modern America. New York: Oxford University Press, 2011.

Duden, Barbara. Disembodying Women: Perspectives on Pregnancy and the Unborn. Translated by L. Hoinacki. Cambridge, MA: Harvard University Press, 1993.

Etude Longitudinal Française depuis l'Enfance. www.elfe-france.fr/index.php/en/.

Fletcher, John. "The Foetus as a Patient: Ethical Issues." Journal of the American Medical Association 246 (1981): 772-773.

Everett, Thomas, and Lyn Chitty. "Cell-Free Foetal DNA: The New Tool in Foetal Medicine." Ultrasound in Obstetrics $\mathcal{E}$ Gynecology 45 (2015): 499-507.

Gregg, Robin. Pregnancy in a High-tech Age: Paradoxes of Choice. New York: New York University Press, 1995.

Haraway, Donna J. Simians, Cyborgs and Women: The Reinvention of Nature. London: Free Association Books, 1991.

Haraway, Donna J. "The Virtual Speculum in the New World Order." Feminist Review 55 (1997): 22-72. 
Kroløkke, Charlotte. "Biotourist Performances: Doing Parenting During the Ultrasound." Text E Performance Quarterly 31.1 (2011): 15-36.

Larkin, Lesley. "Authentic Mothers, Authmetic Daughters and Sons: Ultrasound Imaging and the Construction of Foetal Sex and Gender." Canadian Review of American Studies 36.3 (2006): 273-291.

Layne, Linda. "'He was a Real Baby with Baby Things': A Material Culture Analysis of Personhood, Parenthood, and Pregnancy Loss." Journal of Material Culture 5.3 (2000): 321-345.

Layne, Linda. "Your Child Deserves a Name': Possessive Individualism and the Politics of Memory in Pregnancy Loss." Eds. Gabriele Vom Bruck, and Barbara Bodenhorn. The Anthropology of Names and Naming. Cambridge University Press, 2006. 31-50.

Leaver, Tama. "Intimate Surveillance: Normalizing Parental Monitoring and Mediation of Infants Online." Social Media +Society April-June (2017): 1-10.

Lupton, Deborah. "Digital Sociology: Beyond the Digital to the Sociological." Eds. N. Osbaldiston, C. Strong and H. Forbes-Mewett. The Australian Sociological Association 2013 Conference Proceedings: Reflections, Intersections and Aspirations, 50 Years of Australian Sociology. Melbourne: TASA, 2013a.

Lupton, Deborah. The Social Worlds of the Unborn. UK: Palgrave Macmillan, 2013b.

Lupton, Deborah, Sarah Pedersen, and Gareth Thomas. "Parenting and Digital Media: From the Early Web to Contemporary Digital Society." Sociology Compass 10.8 (2016): 730-743.

Merz, Eberhard, and Jacques Abramowicz. "3D/4D Ultrasound in Prenatal Diagnosis: Is it Time for Routine Use?” Clinical Obstetrics and Gynecology 55.1 (2012): 336-351.

Mills, Catherine. "Making Foetal Person: Foetal Homicide, Ultrasound and the Narrative Significance of Birth." Philosophia Journal 4.1 (2014): 88-107.

Mitchell, Lisa. Baby's First Picture: Ultrasounds and the Politics of Foetal Subject. Toronto University Press, 2001.

Mitchell, Lisa and Georges Eugenia. "Cross-Cultural Cyborgs: Greek and Canadian Women's Discourses on Foetal Ultrasound." Feminist Studies 23.2 (1997): 373-402.

Palmer, Julie. "The 'Technofoetus' as Citizen: The Impact of Three-Dimentional Ultrasound." Eds. Elźbieta H. Oleksy, Andrea Peto and Berteke Waaldijk. Gender and Citizenship in a Multi-Cultural Context. Peter Lang Publishing Group, 2008. 223-232.

Pasche Guignard, Florence. "A Gendered Bun in the Oven. The Gender-Reveal Party as a New Ritualization During Pregnancy." Studies in Religion/Sciences Religieuses 44.4 (2015): 479-500.

Pélage, Agnès, Sara Brachet, Carole Brugeilles, Anne Paillet, Catherine Rollet, and Olivia Samuel. "Alors c'est quoi, une fille ou garcon? Travail de préparation autour du genre pendant la grossesse." Actes de la Recherche en Sciences Sociales 214 (septembre) (2016): 31-45.

Petchesky, Rosalind. "Foetal Images: The Power of Visual Culture in the Politics of Reproduction." Feminist Studies 13.2 (1987): 263-292.

Risman, Barbara. "From Doing to Undoing: Gender as we know it." Gender and Society 23.1 (2009): 81-84.

Roberts, Julie. “Wakey Wakey Baby': Narrating Four-Dimensional (4D) Bonding Scans." Sociology of Health Ẽ Illness 34.2 (2012): 299-314.

Rollet, Catherine, and Agnès Pélage. "Préparer une chamber pour l'enfant à venir, un enjeu de genre?” Stenae 7 (2014): 1-10. http://journals.openedition.org/strenae/1194.

Samuel, Olivia, Sara Brachet, Carole Brugeilles, Anne Paillet, Agnès Pélage, and Catherine Rollet. "Préparer la naissance: une affaire de genre." Politiques sociales et familiales 116 (juin) (2014): 5-14.

Sandelowski, Margaret. "Separate, but Less Unequal: Foetal Ultrasonography and the Transformation of Expectant Mother/Fatherhood." Gender and Society 8.2 (1994): 230-245. 
Stephens, E. "Anatomical Imag(Inari)Es: The Cultural Impact of Medical Imaging Technologies.” Somatechnics 2.2 (2012): 159-170.

Taylor, Janelle S. "Of Sonograms and Baby Prams: Prenatal Diagnosis, Pregnancy, and Consumption." Feminist Studies 26.2 (2000): 391-418.

Taylor, Janelle S. The Public Life of the Foetal Sonogram. Rutgers University Press, 2008.

Tiidenberg, Katrin, and Nancy Baym. "Learn it, buy it, Work it: Intensive Pregnancy on Instagram.” Social Media+Society January-March (2017): 1-13.

West, Candace and Don H. Zimmerman. "Doing Gender." Gender E Society 1.2 (1987): $125-151$

Westbrook, Lauren, and Kristen Schilt. "Doing Gender, Determining Gender: Transgender People, Gender Panics, and the Maintenance of Sex/Gender/Sexuality System." Gender and Society 28.1 (2014): 32-57.

Williams, Clare. "Framing the Foetus in Medical Work: Rituals and Practices." Social Science E Medicine 60.9 (2005): 2085-2095.

\section{ABOUT THE AUTHOR}

Dr. Agnès Pélage is a Senior Lecturer in Sociology currently working at the ENSAE (The French Grande École for Economics, Data Science and Finance). A sociologist of education and family, she is affiliated to the research centre of social sciences, PRINTEMPS, University of Versailles-Saint-Quentin en Yvelines/Paris Saclay.

\section{NOTES}

1 The French Longitudinal Study since Childhood (Elfe) is a national survey designed to study the physical, psychological and social development of all 18,000 babies born in France in 2011 until their $20^{\text {th }}$ birthday.

2 The details of this selection are fully explained in Part 2 of this paper. 